ideal to be aimed at. In effect that method provided a supply of milk of which 2 per cent. came from tuberculin tested cows, and was sold at a price which was beyond the pocket of the average consumer: the remaining 98 per cent. was pasteurized milk. He wished to point out that there was an alternative to this which had been found to be very successful in those districts in which it had received adequate support-namely, the production of Grade A tuberculin tested milk, the price of which was very much less than that of certified milk. In the town of Reading this milk formed not less than one-sixth of the total supply of the town, was sold without treatment, and was purchased by the poor in quantities at least equal to those which were purchased by the rich.

Dr. C. A. Mortlock-Brown (Braunton) called attention to the need for a clean water supply and an incinerator on dairy farms.

Mr. Wilfred Buckley, in reply, said that he proposed in future to test his cattle for tuberculosis-once by the subcutaneous method and once by the intradermal. $\mathrm{He}$ pointed out that under the new Tuberculosis Order the farmer was to be compensated for udder disease and emaciation, instead of being fined or imprisoned. It was not possible to eliminate or isolate all tuberculous cattle. In this country there were about $2,500,000$ milk cows; where were the $1,000,000$ reactors to be put? In matters such as this it was advisable to go reasonably slowly. The percentage of fat in milk could be kept within a limit of variation of $1 / 2$ per cent. if cows could be milked every twelve hours, but conditions of transport and so on did not allow of this: In Mr. Buckley's opinion more suffering was caused by tuberculosis than by other diseases, but some said that there was more disease from dirt. $\mathrm{He}$ protested strongly against the view of some physicians that children could be immunized against tuberculosis by consuming tuberculous milk. It was a view which encouraged bad producers.

Mr. MAGGs was not satisfied with the present state of things. The farmer already helped to eliminate cows by sending them to the butcher; and if Mr. Coleman had not condemned the 164 cows in 1913, the farmer would have condemned them himself. Inspection might be adequate in Liverpool, but this was not so in other places: in many places it was a farce. Consequently he was not impressed by Mr. Quinton's views on legislation, and he asked if there had ever been a prosecution for dirty milk in London.

The Charnman said that the medical profession must stimulate public interest and a public demand. Education was needed both amongst the public and in the medical profession. He disliked the division of milk into grades, as he thought that under ideal conditions the term "milk" should be sufficient. The producer must be able to assure the medical man that his goods would be up to standard. Dr. Flemming wished to add another slogan to that mentioned by Mr. Maggs about the doctornamely, "Dirt in the cup Will send his bill up."

At the end of the afternoon session a visit was paid to the fifteenth century moated manor-house at Great Chalfield, where a demonstration was given of the production of Grade A certified milk.

\section{THE TREATMENT OF HARE-LIP.}

BY

HeNRY F. MacAULEY, M.B., M.Ch., F.R.C.S.I., SURGEON, THE CHILDREN'S HOSPITAL, TEMPLE STREET, DUBLIN; ST. MARY'S OPEN-AIR HOSPITAL, CAPPAGH, ETC.

As many improvements which have been introduced into the operations for the repair of hare-lip-or cleft lip as Brophy ${ }^{1}$ suggests it is more correctly designated-have not yet found their way into the ordinary textbooks, it has seemed worth while to give an account of those that I have found useful.

The age of choice is about 3 months; this can be varied, but it should be remembered that the longer the operation is postponed the larger the cleft becomes. The infant ought to be fed until about two hours before being given the anaesthetic, which should be open ether reinforced subsequently, if necessary, by a few whiffs of chloroform through a Junker's inhaler. I prefer to have the patient upright on the table with the head. supported from behind by a nurse. This prevents the reflux of blood into the pharynx, and aroids pulmonary complications.

\section{Simple, Sinqle Cleft Lip.}

After cleansing the operative field, two stout silk sutures are passed on a curved needle from without inwards and half-way up the lip : near each angle of the mouth; they are tied with a good deal of tension. ${ }^{2}$ Good haemostasis is secured by this method, and if the free ends of the sutures are caught in forceps they will act as efficient retractors. Special forceps are adrocated for the purpose, but in my opinion are inferior to the silk ligatures. The lip and cheek on each side of the cleft is freed from the underlying bone.in the usual way; the extent to which this is carried depends on the size of the cleft; it is particularly necessary to free and bring down an abnormally attached ala nasi.

The next step is to pare the sides of the cleft. Each side of the cleft is incised from the upper end down to the exact line of junction of skin and mucous membrane on the lip margin. The incision separates the red margin of each side of the cleft, and in addition a small triangular area of skin with each. It is essential that the flap be not too slender, as the lip will be liable to part later at the sutured area; or too thick, for then the upper lip wili be too narrow, and subsequently the lower lip will project. It is for the latter reason that $I$ abandoned the use of Thompson's lines, for though they gave a beautiful result in the repaired lip, they caused the sacrifice of too much lip tissue, and when the child was seen after a year or so the lower lip was unduly prominent.

The tips of the free ends of the detached flaps are caught in a pair of Allis's tissue forceps, which will serve to control the flaps and to approximate the raw margins for suturing (Fig. 1). It is to be noticed that so far no tissue has been sacrificed, the flaps having been turned down in their entirety; this is Mayo's method. ${ }^{3}$ Suturing is now proceeded with, fine silkworm gut or horsehair on the skin, and catgut on the mucous membrane side, to close the raw area there and prevent adhesion of the lip to the alveolus. The first suture should be through the skin, emerging exactly at the line of the muco-cutaneous junction on either side of the cleft; the accurate approximation of this line is of the utmost excess of tissue to be removed importance. The second suture is placed at the upper end of the cleft, and it should also be finely adjusted in order to secure a good nostril.

Then when all the suturing is finished except at the free margin the excess of tissue is removed from the flaps by an oblique incision, and the free border of the lip is finished by a mattress stitch of catgut. The small triangles of skin turned down in each flap are removed by the incision together with excess of mucous membrane. A little excess of tissue is left at the free margin; this by Mayo's method is rendered very easy.

The operation described above is for complete single clefts; for incomplete clefts the steps are much the same, but freeing of the cheek from the bone need not be so extensive, and the incisions for the flaps commence above the angle of the cleft, and need not go into the nostril. 
Cleft Lip with Unilateral Detachment of Premaxilla.

If the lip can be repaired without interference with the premaxilla, that bone should not be touched, as in the course of time pressure of the repaired lip will put back the prominent bone into good line. If, however, the prominence is so marked that the lip cannot be repaired over it, or only repaired with considerable tension, then the bone requires replacement. It is, I think, useless to attempt to push the bone back into place unless it is fractured at one end. Various methods of producing the fracture are suggested; probably the following are the best.

Method A.-Make a small incision on the alveolar edge where the interval between the lateral incisor and canine on the attached side of the premaxilla would be expected to lie; there insert a small chisel and fracture the bone sufficiently to allow manual replacement.

Method B.-This method was originated by Mr. Staunton in the Children's Hospital, Dublin, to produce a fracture at the site mentioned and leave the overlying mucous membrane intact. A specially devised forceps is used, one blade of which is broad and specially devised forceps is used, one blade of which is broad and
blunt, while the other has a narrower but blunt edge. The forceps is so made that the blades on full compression do not meet, but sufficient space is left to allow the more elastic soft parts to escape whilst the inelastic bone is fractured.

The usual procedure when the bone has been mobilized sufficiently is to pare the edges of the cleft alveolus on either side and to fix the bone by wiring across the cleft. This method is to be condemned as it is unnecessary and difficult; in perforating the bone for the wire teeth on each side of the cleft are often destroyed or detached, and the wire often cuts through, or a piece of the premaxilla may be detached. It is much better to proceed immediately to do the lip operation, as the repaired lip will then act as an efficient splint.

Cleft Lip with Bilateral Detachment of Premaxilla.

This constitutes the most difficult problem in the surgery of the condition; as the bone is frequently displaced far forwards its reduction and retention in place may be extremely difficult. Of course, if the displacement of the bone is slight it_may be possible to bring the lip over it without interfering otherwise with the bone; this fortunate state of affairs, however, is very unusual, and other methods are generally necessary.

The anterior part of the nasal septum, to which alone the projection is attached, must be divided by making a short incision along the lower edge of the nasal septum right down to the bone, separating the soft tissues from the underlying bone, and dividing the denuded septum for the required extent with a small stout pair of scissors.

In these cases it is practically impossible to avoid retention wire sutures to hold the mobilized bone in place. For this purpose, as the premaxillary segment is so small, I have devised a method in which it is necessary only to pierce that segment once, and only in its central thicker part. The best instrument to use for piercing the bone is a very small sized trocar and cannula, the cannula being without a shoulder so that it can be withdrawn through the bone either outwards or inwards. For ease of insertion and avoidance of undue trauma to the small premaxillary segment, I strongly advise piercing and insertion of the wire through that segment before it has been mobilized by division of the septum. The bone is pierced at its centro by the trocar with cannula attached, and the trocar is withdrawn and the two free ends of a silver wire loop are

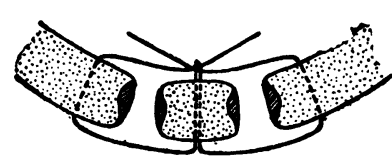

passed from within (from the mouth cavity) outwards, leaving the loop on the in side. Each free end is then drawn in an opposite direction. The superior maxilla Fig. 2.-Horizontal view showing of each side is pierced at method of wiring premaxillary some distance from either element in bilateral detachment. cleft as before, and each free end is returned through the cannula to project on the inside of the mouth. The margins of the cleft are pared, and the suture tightened by drawing the free ends through the loop, pulling them tense, twisting the wire and cutting off any excess (Fig. 2).

The lip may be repaired immediately, or if the ability of the child to stand further operation at the time is questionable, further measures may be delayed for some days.
The repair of the lip defect is carried out as before. The fleshy middle part of the lip attached to the premaxilla is merely freshened by two perpendicular cuts down the sides, and from their lower ends by two angular cuts meeting at the midpoint of the lower border. Mayo's flap method is again employed on the lateral margins of the clefts. Suturing is them carried out, but there is no excess of tissue to be removed. It may be necessary to make lateral cuts into the lip tissue on either side before suturing to secure accurate coaptation of the lateral with the central fleshy segment, and to give fullness to the lip. As even with the premaxilla replaced it is sometimes difficult to avoid tension, it is useful to remember the suggestion of Goyder ${ }^{4}$ in such cases, to do only the repair of one side of the double cleft at the time, and at a subsequent operation, when the wound has soundly healed, to do the other side.

\section{Post-operative Treatment.}

The silk haemostatic sutures at the angles of the mouth are removed immediately on the completion of the operation. The question of fixation of the cheeks by drawing them towards the middle line so as to avoid strain on the suture line has then to be decided. In the majority of my own cases I merely paint the wound with iodine, leave it without covering of any sort, and use no fixation whatever. But if a child is very fretful, and particularly in cases of bilateral clefts, I adopt one of two methods of fixation. The first, by passing two pieces of adhesive plaster, one from the cheek in front of the ear up over the bridge of the nose and down to a corresponding point on the other cheek, the cheeks meanwhile being drawn inwards, and the other from in front of the ear down to the chin and up to a corresponding point on the other side, ${ }^{5}$ to evert the lip and allow a free airway, as well as to aid in relieving tension. The other method also leaves the wound free; it is the use of the Logan traction brace as depicted in Brophy's textbook.

The trend of modern methods in the treatment of the deformity of cleft lip is to use simple methods for the repair of the lip, and to avoid, when at all possible, interference with associated lesions of the alveolus.

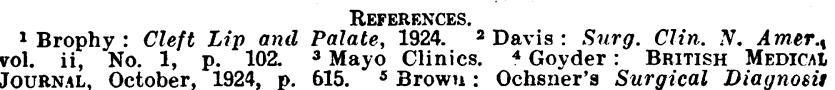
JournaL, October, 1924, p. 615.
and Treatment, vol. $i$, p. 588 .

\section{THE USES OF COELIOSCOPY.}

\section{A. RENDLE SHORT, M.D., B.S., B.Sc., F.R.C.S., SURGEON TO THE BRISTOL ROYAL INFIRMARY.}

As exploratory laparotomy, often referred to as though it were a mere trifle, may be from the patient's point of view a very formidable affair. It involves a general anaesthetic, followed probably by some flatulent discomfort and perhaps anaesthetic vomiting, and two or three weeks in bed, and occasionally some complications with the wound. The expense may be considerable. In cases of carcinoma of the stomach, or malignant pancreas, death may follow so soon after as to raise a suspicion that the operation had something to do with it.

In a certain number of cases, not many perhaps, there is a far less formidable alternative: this is to distend tho abdomen with air, which can be done without serious discomfort under a local anaesthetic through a tiny incision, and to inspect the viscera with a cystoscope. I have been using this method for about a year, and have never seen harm follow. Like every other technical procedure a little trouble must be taken to learn how to get a good view, but it is not more difficult than cystoscopy.

The advantages of coelioscopy over exploratory laparotomy are: (1) it can be done without discomfort under novocain; (2) the incision is so small that it is only neces sary to keep the patient in bed for a day or two; (3) no special instruments are needed; (4) it can be done at the patient's own house; (5) it is available when it would be dangerous to perform laparotomy.

A few examples may be given to illustrate its usefulness. Small malignant nodules have several times been seen on 